\title{
A theoretical evaluation of growth yields of yeasts
}

Cornelis Verduyn, ${ }^{1, *}$ Adriaan H. Stouthamer, ${ }^{2}$ W. Alexander Scheffers ${ }^{1}$ \& Johannes P. van Dijken ${ }^{1}$

${ }^{1}$ Department of Microbiology and Enzymology, Delft University of Technology, Julianalaan 67, 2628 BC Delft, The Netherlands; ${ }^{2}$ Department of Microbiology, Biological Laboratory, Free University, de Boelelaan 1087, $1081 \mathrm{HV}$ Amsterdam, The Netherlands (* requests for offprints)

Received 20 June 1990; accepted 12 November 1990

Key words: yeast, yield, energetics, $\mathrm{P} / \mathrm{O}$-ratio, $\mathrm{Y}_{\mathrm{ATP}}$

\section{Abstract}

Growth yields of Saccharomyces cerevisiae and Candida utilis in carbon-limited chemostat cultures were evaluated. The yields on ethanol and acetate were much lower in S. cerevisiae, in line with earlier reports that site I phosphorylation is absent in this yeast. However, during aerobic growth on glucose both organisms had the same cell yield. This can be attributed to two factors:

- S. cerevisiae had a lower protein content than C. utilis;

- uptake of glucose by $C$. utilis requires energy whereas in $S$. cerevisiae it occurs via facilitated diffusion. Theoretical calculations showed that, as a result of these two factors, the ATP requirement for biomass formation in $C$. utilis is $35 \%$ higher than in $S$. cerevisiae (theoretical $\mathrm{Y}_{\mathrm{ATP}}$ values of 20.8 and 28.1, respectively). The experimental $\mathrm{Y}_{\mathrm{ATP}}$ for anaerobic growth of $S$. cerevisiae on glucose was $16 \mathrm{~g}$ biomass-mol $\operatorname{ATP}^{-1}$.

In vivo $\mathrm{P} / \mathrm{O}$-ratios can be calculated for aerobic growth on ethanol and acetate, provided that the gap between the theoretical and experimental ATP requirements as observed for growth on glucose is taken into account. This was done in two ways:

- via the assumption that the gap is independent of the growth substrate (i.e. a fixed amount of ATP bridges the difference between the theoretical and experimental values).

- alternatively, on the assumption that the difference is a fraction of the total ATP expenditure, that is dependent on the substrate.

Calculations of P/O-ratios for growth of both yeasts on glucose, ethanol, and acetate made clear that only by assuming a fixed difference between theoretical and experimental ATP requirements, the P/O-ratios are more or less independent of the growth substrate. These $\mathrm{P} / \mathrm{O}$-ratios are approximately $30 \%$ lower than the calculated mechanistic values.

\section{Introduction}

In the seventies much attention has been paid to the potential use of microorganisms as a source of single-cell protein (SCP). However, the costs of the processes developed were too high for SCP to com- pete with other sources of protein, such as soybeans.

The only profitable SCP process carried out on an industrial scale is the production of baker's yeast. The product is mainly used as a biocatalyst in the rising of dough (Beudeker et al. 1990). An 
important aspect of baker's yeast production, and of SCP production in general, is that the price of the final product is governed to a large extent by the price of the raw materials, notably the molasses.

Studies on the bioenergetics of microbial metabolism are important for practical purposes, since they indicate the limits to which the cell yield can be improved by physiological or genetical manipulations. It has been shown, for instance, that in methylotrophic organisms the biochemistry of the assimilation route of methanol has a significant effect on the cell-yield (Harder \& van Dijken 1976; Harder et al. 1981). However, the assimilation pathway (s) of more common carbon sources for growth of yeasts (like glucose, glycerol, ethanol) are generally very similar in different yeast species. Therefore, the differences in cell yield observed in yeasts can generally not be explained by differences in anabolic pathways.

In this study the effect of a number of characteristics affecting bioenergetics, such as mechanism of solute transport, cell composition, and efficiency of oxidative phosphorylation, will be discussed on the basis of a comparative study on cell yields of two industrially important yeasts: Saccharomyces cerevisiae ('baker's yeast') and Candida utilis ('fodder yeast').

\section{Materials and methods}

\section{Organisms and growth conditions}

Saccharomyces cerevisiae CBS 8066 and Candida utilis CBS 621 were obtained from the Centraal Bureau voor Schimmelcultures, Yeast Division, Delft, The Netherlands, and maintained on agar slants at $4^{\circ} \mathrm{C}$.

The yeasts were grown in aerobic $(60-80 \%$ of air saturation) carbon-limited chemostat cultures at $\mathrm{pH}$ 5.0 and $30^{\circ} \mathrm{C}$ in mineral medium as described by Postma et al. (1989). Unless mentioned otherwise, the dilution rate was $0.10 \mathrm{~h}^{-1}$. The carbon and energy source was glucose $\left(5 \mathrm{~g} \cdot 1^{-1}\right)$, glycerol $\left(5 \mathrm{~g} \cdot 1^{-1}\right)$, ethanol $\left(3.5 \mathrm{~g} \cdot 1^{-1}\right)$, or acetic acid $\left(7.5 \mathrm{~g} \cdot 1^{-1}\right)$. This resulted in a biomass concentration of approximately
$2.5 \mathrm{~g} \cdot 1^{-1}$. In case of growth on ethanol, the reservoir vessel was placed in a refrigerator. In all cases ammonium sulphate $\left(5 \mathrm{~g} \cdot 1^{-1}\right)$ was used as nitrogen source.

Biomass yields were determined in triplicate; the variation was less than $3 \%$. Yields were also determined with only half the amount of carbon source added; no differences were observed as compared to the yields with standard amounts, thus confirming carbon-limited growth conditions.

\section{Analytical methods}

Glucose, glycerol and acetate were determined with Boehringer test-kits no. 676543, 148270 and 148261 , respectively. Ethanol was assayed colorimetrically according to Verduyn et al. (1984).

Protein content of biomass was assayed with a modified biuret method: a $10 \mathrm{ml}$ sample of culture fluid (2-3 g. $1^{-1}$ dry weight) was washed twice with distilled water and concentrated twice. The concentrate was boiled in $1 \mathrm{M} \mathrm{NaOH}$ (final concentration) for $10 \mathrm{~min}$ and subsequently cooled on ice. $\mathrm{CuSO}_{4} \cdot 5 \mathrm{H}_{2} \mathrm{O}$ was added to a final concentration of $25 \mathrm{mM}$. After $5 \mathrm{~min}$ at room temperature, the mixture was centrifuged in an Eppendorf table top centrifuge $(13,000 \mathrm{rpm})$ for $2 \mathrm{~min}$ and the absorbance of the supernatant was read at $550 \mathrm{~nm}$ with a spectrophotometer. Variation in duplicate samples was less than $5 \%$.

The carbon, hydrogen and nitrogen contents of biomass were determined with an Elemental Analyser 240B (Perkin Elmer). Before analysis, fresh cell samples were washed twice with distilled water and dried at $70^{\circ} \mathrm{C}$ for $48 \mathrm{~h}$. The elemental composition of biomass was calculated from an analysis of the contents in carbon, hydrogen and nitrogen. Oxygen content was calculated on the assumption that $\mathrm{C}, \mathrm{H}, \mathrm{N}$ and $\mathrm{O}$ make up $94 \%$ of the dry weight (including ash; cf. Verduyn et al. 1990a). Oxygen consumption and carbon dioxide production were determined and calculated according to van Urk et al. (1988). 
Calculations of theoretical energy requirements for biomass formation

The calculations on the theoretical $Y_{A T P}^{\max }$ for aerobic growth are similar to those for anaerobic situations and have already been described in detail previously (Verduyn et al. 1990b). A difference between aerobic and anaerobic growth lies in the synthesis of lipids. Under anaerobic conditions, it can be assumed that all lipid in biomass is formed from oleic acid in the medium. For the lipid composition under aerobic conditions, a simplification has been made according to Bruinenberg et al. (1983), in that all lipid is assumed to be in the form of triglycerides with three long-chain neutral fatty acids; i.e.: palmitoleic acid 13.7; linoleic acid 5.5; oleic acid 8.2 ; and giycerol $9 \mathrm{mmol} \cdot 100 \mathrm{~g}^{\text {cells }}{ }^{-1}$. Actually most lipid in chemostat-grown yeasts consists of phospholipids with a polar head (like phosphatidyl choline) and fatty acyl residues that are unsaturated to a large extent. However, the fatty acyl residues make up the major weight fraction of phospholipids. This simplification does not significantly affect calculations on the overall energetics of biomass formation. Fatty acid synthesis cannot proceed directly from mitochondrial acetyl-CoA, since this compound cannot cross the mitochondrial membrane to the cytosol, where the actual fatty acid synthesis takes place. Instead, acetyl-CoA first has to be converted into citrate, which then crosses the membrane and is split into acetyl-CoA and oxaloacetate (OAA) by ATP-dependent citrate lyase (E.C.4.1.3.8.); this requires a net input of 1 ATP per acetyl-CoA synthesized (Evans et al. 1983). OAA may then re-enter the mitochondrion where it can be used to form another citrate with a new acetyl-CoA. An average fat content of approximately $7 \%$ for non-oleaginous yeasts as reported by Oura (1972) has been used.

The biosynthesis and composition of the other main cell components, i.e. protein, carbohydrate, and RNA (assumed to be $7 \%$ of dry weight at $\mathrm{D}=$ $0.10 \mathrm{~h}^{-1}$ ), as well as the transport costs of nutrients other than the carbon sources, have been discussed elsewhere (Verduyn et al. 1990b).

\section{Results and discussion}

A comparison between theoretical and experimental growth yields is complicated by the fact that growth yields in aerobic organisms depend on both the energy requirement for biosynthesis $\left(\mathrm{Y}_{\mathrm{ATP}}\right)$ and the ATP yield of respiration (P/O-ratio), according to the equation:

$$
\mathrm{Y}_{\mathrm{ATP}}=\mathrm{Y}_{\mathrm{O}} \cdot(\mathrm{P} / \mathrm{O})^{-1} .
$$

This equation represents the most simple case of a substrate for which the dissimilation does not yield ATP by substrate phosphorylation, as is the case for methanol.

However, neither the $\mathrm{Y}_{\mathrm{ATP}}$ not the P/O-ratio can be determined independently of each other in aerobic cultures. In the case of fermentable substrates, this problem can be circumvented by determining $\mathrm{Y}_{\mathrm{ATP}}$ anaerobically in continuous culture and using this value for the aerobic situation to calculate the P/O-ratio.

ATP requirement for anaerobic chemostat growth of $S$. cerevisiae on glucose

Estimates of $\mathrm{Y}_{\text {ATP }}$ in anaerobic $S$. cerevisiae cultures average 10.5-11 $\mathrm{g}$ biomass $\cdot \mathrm{mol}^{\mathrm{ATP}}$ formed $^{-1}$ (Bauchop \& Elsden 1960; Kormančhíková et al. 1969). However, these results were obtained from batch cultures, in which the $Y_{\text {ATP }}$ strongly depends on the time of harvesting as shown by Haukeli \& Lie (1971). These authors observed a continuous decrease in $\mathrm{Y}_{\text {ATP }}$ of various yeast strains as a function of the number of generations. Although no explanation has been offered for this phenomenon, it could point to a medium limitation. Reliable data can only be obtained under energy limitation in sugar-limited chemostat cultures, that is when it can be shown that the biomass concentration in the culture is linearly proportional to the amount of carbon- and -energy source provided. From analytical data on anaerobic growth of $S$. cerevisiae $\mathrm{H} 1022$ in chemostat cultures by Schatzmann (1975), a $Y_{\text {ATP }}$ of approximately 16.5 can be calculated at a dilution rate of $0.10 \mathrm{~h}^{-1}$. Indeed, a value of $15.8 \pm 0.6$ has 
been reported for this strain (Verduyn et al. 1990b). A $\mathrm{Y}_{\mathrm{ATP}}$ of $14.0 \pm 0.5$ was found for $S$. cerevisiae CBS 8066, which had a slightly higher protein content. However, this latter strain produced acetate and it was calculated that $\mathrm{Y}_{\mathrm{ATP}}$ corrected for uncoupling by acetate was approximately $15 \pm 0.5 \mathrm{~g}$ biomass'mol ATP-1. The 'true' $\mathrm{Y}_{\text {ATP }}$ (i.e. without uncoupling by acetic acid) thus appears very similar for both strains and is assumed to be $16 \mathrm{~g}$ biomass- mol ATP formed ${ }^{-1}$ at a dilution rate of $0.10 \mathrm{~h}^{-1}$ (Verduyn et al. 1990b).

If the maintenance energy (Pirt 1965) is known, the experimental $\mathrm{Y}_{\mathrm{ATP}}^{\max }$ can be calculated according to:

$$
\begin{aligned}
& \text { observed }\left(\mathrm{Y}_{\mathrm{ATP}}\right)^{-1}=\mathrm{m}_{\mathrm{ATP}} \cdot \mu^{-1}+ \\
& \text { experimental }\left(\mathrm{Y}_{\mathrm{ATP}}^{\max }\right)^{-1} \text {. }
\end{aligned}
$$

However, as discussed previously (Verduyn et al. $1990 \mathrm{~b}$ ), the correction of $Y_{\mathrm{ATP}}$ for maintenance has only a small effect on the final value. It was shown that the actual maintenance could not be determined accurately during growth on glucose, due to the fact that the biomass composition of $S$. cerevisiae CBS 8066 changes with the dilution rate under anaerobic conditions (Verduyn et al. 1990a). Such a change in biomass composition also occurs under aerobic conditions (Fiechter \& von Meyenburg 1969; Furakawa et al. 1983; Verduyn, results not published). From the results presented for aerobic chemostat growth of $S$. cerevisiae 8066 it is obvious that, even down to a dilution rate of $0.05 \mathrm{~h}^{-1}$, the effect of maintenance cannot be observed either (Postma et al. 1989). According to values reported in the literature, the maintenance of yeasts is small as compared to that in most bacteria. Hence, the influence of the maintenance on bioenergetics of yeasts appears to be small as already discussed by various authors (Lagunas \& Ruiz 1988; Roels 1983). In this study the effect of maintenance will consequently be neglected.

\section{Theoretical analysis of biomass formation from glucose}

The theoretical energy requirement for the forma- tion of $100 \mathrm{~g}$ of $S$. cerevisiae CBS 8066 during anaerobic glucose-limited chemostat growth has been calculated as $28.3 \mathrm{~g}$ biomass $\cdot \mathrm{mol} \mathrm{ATP} \mathrm{AT}^{-1}$ at a dilution rate of $0.10 \mathrm{~h}^{-1}$ (Verduyn et al. 1990b). This value is much higher than the experimental value of 16 (see previous section). Therefore, either more ATP is required for the synthesis of certain cell components, or part of the ATP produced during dissimilation is expended in processes that do not lead to biomass formation. This is sometimes indicated as 'uncoupling between energy generation and biomass formation'. Little progress has been made in identifying the nature of this uncoupling, although a number of processes which could contribute have been proposed (Lagunas 1976; Lagunas \& Ruiz 1988; Stouthamer 1979; Tempest \& Neijssel (1984). However, since there is insufficient information so far about the magnitudes or relative contribution of any of these factors (including amongst others futile cycles and permeability of membranes to protons) this will not further be discussed here.

Experimental analysis of growth yields of yeasts in aerobic carbon- and energy-limited chemostat cultures

It is evident from previous calculations on bioenergetics (e.g. Babel \& Müller 1985; Stouthamer 1973; Verduyn et al. 1990b) that the polymer composition has a major impact on the theoretical energy requirement for cellgrowth. During growth on glucose, the polymerization of amino acids as well as the transport of various nutrients represent a large fraction of the total calculated ATP requirement. Hence it is important to include the polymer composition in theoretical considerations on bioenergetics. Since a survey of literature data indicates that, on an average, the RNA- and lipid contents of yeasts grown in continuous culture are virtually similar (cf. Verduyn et al. 1990b for references), only the actual protein content has been measured in this study. Furthermore, small variations in RNA and lipids hardly influence the final ATP requirement. An additional reason to measure the protein content is that literature data in- 
dicate large differences in the protein content of various yeasts; even during chemostat growth of various $C$. utilis strains under supposedly carbonlimited conditions, protein contents reported varied from 34\% (Brown \& Rose 1969) to 56\% (Shulgo'vskaya et al. 1988).

We have determined the cell yields for $S$. cerevisiae and $C$, utilis during carbon-limited chemostat growth at a dilution rate of $0.10 \mathrm{~h}^{-1}$ for a number of carbon sources (Table 1). In addition, the protein and nitrogen-contents were also determined. A constant ration of $5.4 \pm 0.2$ was observed between the contents of protein and nitrogen (Table 1). It is evident that the yield on some carbon sources (e.g. ethanol) can be quite different for both yeasts. Nevertheless, as far as is known, their assimilation routes are the same. It must be concluded that other factors determine the differences in cell yield, for instance the efficiency of respiration. The reverse is not true: similar yields (as during growth on glucose; Table 1) does not mean that the efficiencies of respiration are also similar. It is well known that $S$. cerevisiae lacks site I (Ohnishi 1973), whereas this is present in C. utilis (Aiking et al. 1977; Light \& Garland 1971).

\section{Theoretical comparison of the energy requirements} for aerobic glucose-limited growth of $S$. cerevisiae and $C$. utilis

The calculated ATP requirement for the formation of biomass during aerobic growth on glucose of $S$. cerevisiae and $C$. utilis is shown in Table 2. The overall theoretical energy requirement for $C$. utilis is considerably higher than for $S$. cerevisiae. This is due to the fact that the protein content of $C$. utilis is $25 \%$ higher than that of $S$. cerevisiae (Table 1), and as a consequence more energy is required in the synthesis, and especially in the polymerization, of amino acids. In addition, the higher protein content also necessitates an increased ammonium uptake, which is an energy-requiring process. The most significant difference, however, lies in the fact that, in contrast to S.cerevisiae which takes up glucose by facilitated diffusion (Lang \& Cirillo 1987; Romano 1982), C. utilis exhibits active transport of glucose (Eddy \& Hopkins 1985; Peinado et al. 1989; Postma et al. 1988). Therefore, with an $\mathrm{H}^{+} /$ ATP stoichiometry of the plasma membrane ATPase of 1 (Malpartida \& Serrano 1981; Nelson \& Taiz 1989; Perlin et al. 1986), and a $\mathrm{H}^{+}$/sugar stoichiometry of 1 (Peinado et al. 1989), the transport on one mol of glucose requires $1 \mathrm{~mol}$ ATP.

Thus, despite the same yield on glucose (Table 1), the energy requirements for the formation of a given amount of biomass are quite different for both yeasts (Table 2 ).

\section{Calculation of P/O-ratios for growth on glucose}

Previously, several methods have been used to calculate the effective (in vivo) $\mathrm{P} / \mathrm{O}$-ratio in microorganisms. The method developed by von Meyenburg (1969) involved the construction of gas balances for $S$. cerevisiae at a number of different dilution rates, both in the fully respiratory range of

Table 1. Cell yields ( $\mathrm{g}$ biomass.g carbon source ${ }^{-1}$ ), and contents of protein and nitrogen (expressed as \% of dry weight) of $S$. cerevisiae CBS 8066 and $C$. utilis CBS 621 grown in carbon-limited chemostat cultures at a dilution rate of $0.10 \mathrm{~h}^{-1}$.

\begin{tabular}{llllll}
\hline Organism & C-source & Yield & Protein & Nitrogen & Protein/nitrogen \\
\hline S. cerevisiae & Glucose & 0.51 & 42 & 7.6 & 5.5 \\
& Glycerol & no growth & & & \\
& Ethanol & 0.61 & 46 & 8.6 & 5.4 \\
C. utilis & Acetic acid & 0.29 & 47 & 5.9 & 5.3 \\
& Glucose & 0.51 & 52 & 9.8 & 5.3 \\
& Glycerol & 0.58 & 52 & 9.7 & 5.4 \\
& Ethanol & 0.69 & 53 & 9.8 & 5.3 \\
& Acetic acid & 0.39 & & 5.5 & \\
\hline
\end{tabular}


growth rates, and in the range where fermentation and respiration coexist. He assumed that $Y_{\text {ATP }}$ should be constant at all growth rates and that only for one value of $\mathrm{P} / \mathrm{O}$ this condition could be fulfilled. Indeed this seemed the case at a P/O of approximately 1 . Unfortunately, later research into the physiology of $S$. cerevisiae at different dilution rates has shown that the original gas data obtained by von Meyenburg only represent 'transient' states (Barford \& Hall 1979; Rieger et al. 1983). Furthermore, it is highly unlikely that $\mathrm{Y}_{\text {ATP }}$ is constant at all growth rates, since it is well known that the protein content of $S$. cerevisiae increases significantly with increasing growth rate (Furukawa et al. 1983; Verduyn et al. 1990a; Fiechter \& von Meyenburg 1969), both under anaerobic and aerobic conditions. Therefore a decrease in $\mathrm{Y}_{\mathrm{ATP}}$ is expected with increasing growth rate (cf. Table 2). This has indeed been confirmed: in anaerobic glucose-limited chemostat cultures of $S$. cerevisiae, $\mathrm{Y}_{\mathrm{ATP}}$ decreases with increasing growth rate (Verduyn et al. 1990b).

Harder \& van Dijken (1976) introduced the socalled 'coupling factor' (k) which was based upon the observation that, for growth on glucose, the observed and theoretical values for $Y_{A T P}^{\max }$ differed by about a factor of two: the average experimental $Y_{A T P}^{\max }$ (which has mainly been determined for bacteria) is $12-16 \mathrm{~g}$ biomass $m$ mol ATP formed ${ }^{-1}$ (van Gent-Ruyters et al. 1975; Stouthamer \& Bettenhaussen 1975) and the theoretical value for a 'typical' bacterium is approximately 28 as calculated by Stouthamer (1973). Therefore the equation

$$
\left(\mathrm{Y}_{\mathrm{ATP}}\right)^{-1}=\mathrm{m}_{\mathrm{e}} \cdot \mu^{-1}+\mathrm{k} \cdot\left(\mathrm{Y}_{\mathrm{ATP}}^{\max }\right)^{-1}
$$

was introduced $(k=14 / 28=0.5)$. This equation was subsequently used to calculate $\mathrm{Y}_{\text {ATP }}$ for other substrates than glucose (Babel \& Müller 1985; Dijkhuizen et al. 1977). In effect the use of a coupling factor means that a fraction of all ATP produced in the dissimilation (including that formed by substrate phosphorylation) is subsequently lost in an unidentified manner. There is a peculiar inconsistency in the use of this k-factor: ATP formed by substrate phosphorylation in anabolic processes is supposed to be used stoichiometrically (no k- factor is applied), whereas ATP formed during catabolism is not (a k-factor is applied).

Finally, a third method has been proposed by Harder et al. (1981). This method is based on the assumption that the effective $\mathrm{P} / \mathrm{O}$ is much lower than the mechanistic value, because of a poor coupling between respiration and ATP formation, i.e. a poor efficiency of energy generation. Calculations were then performed with a $\mathrm{P} / \mathrm{O}$ which was $50 \%$ of the assumed mechanistic P/O-ratio (maximal value with full coupling), which at that time was assumed to be 2 and 3 for two or three sites, respectively. This method can be represented by the equation $\left(m_{e}\right.$ has been omitted):

$$
\left(\mathrm{Y}_{\mathrm{ATP}}\right)^{-1}=\mathrm{Y}_{\mathrm{O}} \cdot(\mathrm{k} \cdot \text { mechanistic } \mathrm{P} / \mathrm{O})^{-1}
$$

A considerable number of theoretical studies have been published on this subject (e.g. Gunter \& Jensen 1986; Roels 1983; Stucki 1980). The general conclusion from these studies is that the effective P/O-ratio will be considerably lower than the mechanistic value. There is no agreement, however, on the efficiency of energy generation in vivo, various estimates of an effective $\mathrm{P} / \mathrm{O}$-ratio ranging between $50 \%$ and $80 \%$ of the mechanistic value

Table 2. Calculation of the theoretical $Y_{A T P}^{\max }$ for $S$. cerevisiae and C. utilis during aerobic glucose-limited chemostat growth at a dilution rate of $0.10 \mathrm{~h}^{-1}$.

\begin{tabular}{lcc}
\hline & S. cerevisiae & C.utilis \\
\hline Amino acid synthesis & 162 & 200 \\
polymerization & 1587 & 1960 \\
Carbohydrate synthesis & 482 & 358 \\
Lipid synthesis & 179 & 179 \\
RNA synthesis & 135 & 135 \\
polymerization & 47 & 47 \\
Turnover of m-RNA & 71 & 71 \\
NADPH generation & 77 & 88 \\
Transport: Glucose & 0 & 822 \\
$\quad$ Ammonium & 580 & 700 \\
$\quad$ Potassium and & 240 & 240 \\
$\quad$ phosphorus & & \\
Total & 3560 & 20.8 \\
Theoretical YarP & 28.1 & \\
\hline
\end{tabular}

Data are expressed as mmol ATP. $100 \mathrm{~g}$ bjomass $^{-1}$. 
(Harder et al. 1981; Roels 1983; Stucki 1980). Unfortunately, mechanistic $\mathrm{P} / \mathrm{O}$-ratios are still used in many calculations on bioenergetics, and this consequently leads to low $\mathrm{Y}_{\text {ATP }}$-values. No doubt, part of the confusion arises from the fact that the use of a P/O-ratio of 1.8-2.0 leads to a $\mathrm{Y}_{\mathrm{ATP}}$ of approximately $10-11 \mathrm{~g}$ biomass $\cdot \mathrm{mol} \mathrm{ATP}{ }^{-1}$, which is generally believed to be the correct value for anaerobic growth of yeasts on glucose, even though higher values have been reported (see Haukelie \& Lie 1971 for references).

At this point a different approach should be considered, which has not been reported in the literature so far. The difference between the theoretical and the experimetal ATP requirements might be an approximately constant (fixed) amount of ATP, independent of the carbon source employed. It is obvious that the knowledge of cellular processes is still far from complete. Therefore, theoretical calculations on $Y_{A T P}^{\max }$ do not cover all cellular processes which require an input of energy. In this respect one can think of intracellular transport both of metabolites and of proteins (across vacuolar and mitochondrial membranes, for instance), and of proofreading in protein synthesis. At least part of the gap between the theoretical and experimental ATP requirements might be due to such processes.

In our study, the relation between the $\mathrm{P} / \mathrm{O}$-ratio and the cell yield is calculated basically according to van Dijken \& Harder (1975). This involves calculation, for assumed values of the P/O-ratio, of the amount of glucose to be dissimilated for the energy production, starting from a given $\mathrm{Y}_{\mathrm{ATP}}$ (as determined for anaerobic growth). This amount is then added to the amount required for biosynthetic purposes as obtained from an assimilation equation. The yield can then be calculated. The reducing equivalents required for ATP production originate from two sources: Firstly, a net production of $\mathrm{NADH}$ and/or FADH is obtained in the overall anabolic reactions of most carbon sources commonly employed for yeast growth (Bruinenberg et al. 1983; Gommers et al. 1988). The assimilation equation for the production of $100 \mathrm{~g}$ biomass of $S$. cerevisiae 8066 , including glucose required for the formation of NADPH (as calculated according to Verduyn et al. 1990a), is given by:

$$
\begin{aligned}
& 775 \mathrm{C}_{6} \mathrm{H}_{12} \mathrm{O}_{6}+540 \mathrm{NH}_{3} \rightarrow \\
& 1000 \mathrm{C}_{3.75} \mathrm{H}_{6.6} \mathrm{O}_{2.18} \mathrm{~N}_{0.54}(100 \text { g biomass })+ \\
& 902 \mathrm{CO}_{2}+1426 \mathrm{NADH}+735 \mathrm{H}_{2} \mathrm{O}
\end{aligned}
$$

The surplus of reducing equivalents produced during anabolic reactions may be oxidized to provide energy. However, this yields insufficient energy to cover the requirements for biomass formation.

Secondly, reducing equivalents are provided by dissimilation. For example, with a $\mathrm{Y}_{\mathrm{ATP}}$ of 16,6250 mmol ATP are required for the formation of $100 \mathrm{~g}$ biomass. During anabolic reactions $1426 \mathrm{mmol}$ NADH are produced (Equation 1). With a (chosen) effective P/O-ratio of 1.0 , this would yield $1426 \mathrm{mmol}$ ATP, so still $4824 \mathrm{mmol}$ ATP must be obtained via dissimilation of glucose. One mmol of glucose yields 16 ATP (including 4 by substrate phosphorylation). Hence the amount of glucose required is $4824 / 16=302 \mathrm{mmol}$, and this has to be added to the amount required for anabolic reactions as given in the assimilation equation. Thus, overall $1077 \mathrm{mmol}$ glucose (or $194 \mathrm{~g}$ ) is required for the formation of $100 \mathrm{~g}$ biomass. The yield will then be $100 / 194=0.52 \mathrm{~g}$ biomass $\cdot \mathrm{g}$ glucose ${ }^{-1}$. In this way the cell yield has been calculated as a function of the P/O-ratio (Fig. 1). The experimental yield was 0.51 g cells.g glucose ${ }^{-1}$ (Table 1 ), corresponding to an effective $\mathrm{P} / \mathrm{O}$-ratio of approximately 0.95 (Fig. 1).

Similar calculations for $C$. utilis are complicated by the fact that anaerobic growth of this yeast is either not observed (van Dijken \& Scheffers 1986), or only occurs at extremely low growth rates (Haukeli \& Lie 1971). Therefore, $Y_{\text {ATP }}$ cannot be accurately determined experimentally for $C$. utilis. It is, however, possible to calculate the experimental $\mathrm{Y}_{\text {ATP }}$ on the basis of a ' $\mathrm{k}$ '-factor. Alternatively, as discussed above, it can be assumed that there is a fixed difference between theoretical and experimental ATP-requirements. The value of 0.5 for $\mathrm{k}$ as originally used by Harder \& van Dijken (1976) has been modified to 0.57 . This value is obtained by dividing the experimental $\mathrm{Y}_{\mathrm{ATP}}$ of approximately 16 (obtained from anaerobic glucose-limited chemostat experiments with $S$. cerevisiae at a dilution rate of $0.10 \mathrm{~h}^{-1}$, Verduyn et al. 1990b) by the theoretical $Y_{A T P}^{\max }$ of approximately 28 (Table 2 ). With these 


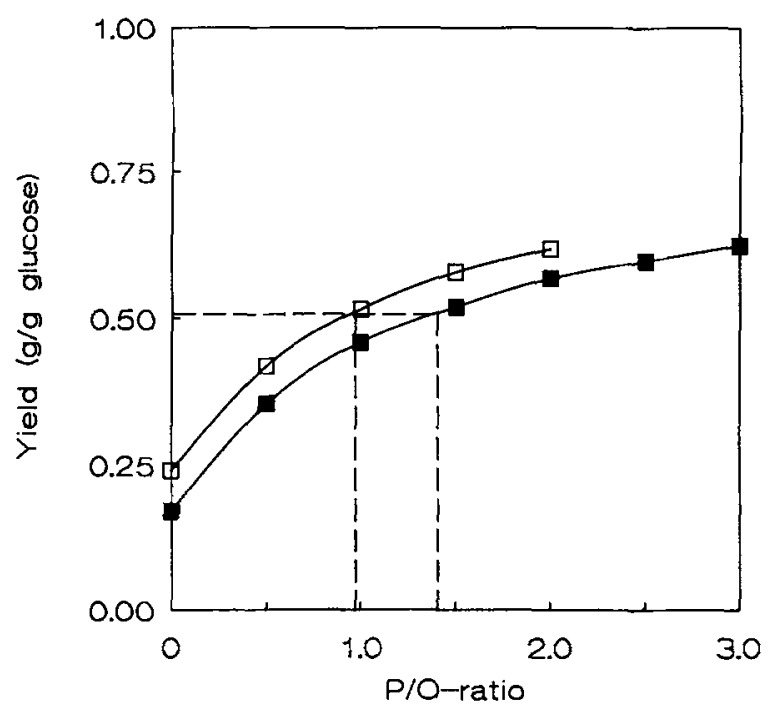

Fig. 1. Calculated cell yield ( $\mathrm{g}$ biomass $\cdot \mathrm{g} \mathrm{glucose}^{-1}$ ) as a function of the $\mathrm{P} / \mathrm{O}$-ratio for $\mathrm{S}$. cerevisiae $(\square)$ and $C$. utilis (G), assuming a fixed difference between the theoretical and the experimental ATP requirements of 2700 ATP $100 \mathrm{~g}_{\text {biomass }}{ }^{-1}$. The dashed lined indicate the observed growth yields in carbon-limited chemostat culture at $\mathrm{D}=0.10 \mathrm{~h}^{-1}$, and the corresponding $\mathrm{P} / \mathrm{O}$ ratio.

values of 16 and 28 , the difference is $2700 \mathrm{ATP} \cdot 100 \mathrm{~g}$ biomass $^{-1}$. The calculations for the relation between the cell yield and the P/O-ratio for $C$. utilis will be based on the latter data. Thus, the energy requirement for the formation of $100 \mathrm{~g}$ biomass is assumed to be the theoretical amount of 4800 (Table 2$)+2700=7500$ ATP $\cdot 100 \mathrm{~g} \mathrm{biomass}^{-1}\left(\mathrm{a} \mathrm{Y}_{\mathrm{ATP}}\right.$ of 13.3). If the $\mathrm{k}$-factor had been chosen, the final result would have been lower: $0.57 \times 20.8=11.9$ ). The calculations are basically similar to those for $S$. cerevisiae, but it should be kept in mind that transport of each molecule of glucose in $C$. utilis requires 1 ATPeq., i.e. with a P/O-ratio of 1.0 only 15 rather than $16 \mathrm{mmol}$ ATP will be formed per mmol glucose dissimilated. The assimilation equation for $C$. utilis can be represented by:

$$
\begin{aligned}
& 821 \mathrm{C}_{6} \mathrm{H}_{12} \mathrm{O}_{6}+700 \mathrm{NH}_{3} \rightarrow \\
& 1000 \mathrm{C}_{3.9} \mathrm{H}_{6.6} \mathrm{O}_{1.93} \mathrm{~N}_{0.70}+1026 \mathrm{CO}_{2}+ \\
& 1038 \mathrm{H}_{2} \mathrm{O}+1638 \mathrm{NADH}
\end{aligned}
$$

With the yield of $0.51 \mathrm{~g}$ biomass $\mathrm{g}$ glucose $\mathrm{e}^{-1}$ (Table 1), the effective $\mathrm{P} / \mathrm{O}$-ratio is approximately 1.4 (Fig. 1). With a $Y_{\text {ATP }}$ of 11.9 obtained via the application of a $\mathrm{k}$-factor, the effective $\mathrm{P} / \mathrm{O}$-ratio would be about 1.6.

\section{Growth yields on two-carbon compounds}

Many studies on the bioenergetics of microorganisms have focussed on growth on methanol, due to the potential use of this cheap raw material as a carbon source for the production of single-cell protein. Little attention has been paid to other carbon sources, in particular those requiring gluconeogenesis. Nevertheless, growth on, for instance, ethanol or acetate is interesting, since it follows quite different pathways from those of glucose. It may therefore provide an 'independent' assessment of, for instance, the applicability of a coupling factor. Pathways for growth of yeasts on ethanol and acetate are very similar, as ethanol is converted into acetate via NAD-alcoholdehydrogenase and NAD (P)-acetaldehyde dehydrogenases.

The assimilation of ethanol for $S$. cerevisiae can be described by:

$$
\begin{aligned}
& \left.2584 \mathrm{C}_{2} \mathrm{H}_{6} \mathrm{O}+610 \mathrm{NH}_{3}+1672 \mathrm{H}_{2} \mathrm{O}\right) \rightarrow \\
& 1000 \mathrm{C}_{4} \mathrm{H}_{6.5} \mathrm{O}_{1.94} \mathrm{~N}_{0.61}+1168 \mathrm{CO}_{2}+ \\
& 1100 \mathrm{FADH}+5989 \mathrm{NADH}
\end{aligned}
$$

and for C. utilis:

$$
\begin{aligned}
& 2544 \mathrm{C}_{2} \mathrm{H}_{6} \mathrm{O}+700 \mathrm{NH}_{3}+1606 \mathrm{H}_{2} \mathrm{O} \rightarrow \\
& 1000 \mathrm{C}_{3.9} \mathrm{H}_{6.5} \mathrm{O}_{1.93} \mathrm{~N}_{0.70}+1188 \mathrm{CO}_{2}+ \\
& 1108 \mathrm{FADH}+5880 \mathrm{NADH}
\end{aligned}
$$

In these calculations it is assumed that NADPH is provided via NADP-acetaldehyde reductase, which is present at high activities during growth of yeasts on ethanol (Bruinenberg et al. 1983) so that involvement of the hexose monophosphate pathway for the production of NADPH is not required. It is furthermore assumed that NADPH-production via this route is exactly balanced with consumption, i.e. that the fraction of ethanol oxidized via the NADP-dependent enzyme exactly covers the need for NADPH, while the remainder of the ethanol is oxidized via NAD-acetaldehyde dehydrogenase. With Equations 3 and 4, the relation 
between the P/O-ratio and the cell yield can now be determined. This has been done for two estimates of the experimental $Y_{A T P}^{\max }$ :

- assuming a ' $\mathrm{k}$ '-factor of 0.57 , and

- assuming a fixed difference of $2700 \mathrm{mmol}$ ATP. $100 \mathrm{~g}$ biomass $^{-1}$ between the theoretical and the experimental ATP requirements.

The theoretical $Y_{\text {ATP }}^{\max }$ is similar for both yeasts and has a value of $9.5 \mathrm{~g}$ biomass $\cdot \mathrm{mol} \mathrm{ATP} \mathrm{AT}^{-1}$ (Table 3 ). This value is much lower than that found for glucose, which is due to the high energy requirements for activation of acetate (net input of 2 ATP) and the high ATP-requirement for gluconeogenesis. With an experimental yield of $0.61 \mathrm{~g}$ biomass $\mathrm{g}$ ethanol $^{-1}$ for $S$. cerevisiae (Table 1) the values for the effective $\mathrm{P} / \mathrm{O}$ are 1.5 (with $\mathrm{k}$-factor) and 1.0 (with fixed difference), respectively (Fig. 2). Thus, with low $Y_{A T P}^{\max }$-values, taking either a fraction or a fixed difference of the theoretical value gives quite different results for the actual $\mathrm{P} / \mathrm{O}$-ratio. The same conclusion can be drawn for $C$. utilis (yield $0.69 \mathrm{~g}$ biomass. $g$ ethanol ${ }^{-1}$, Table 1 ) with effective $\mathrm{P} / \mathrm{O}$ values of 1.8 and 1.3, respectively (Fig. 2).

A comparison of Figs 1 and 2 shows that growth on ethanol reaches a maximal yield which becomes independent of the P/O-ratio, whereas the yield for

Table 3. Energy requirements for the formation of $100 \mathrm{~g}$ biomass from ethanol and acetate (assuming passive uptake) for $S$. cerevisiae and $C$. utilis.

\begin{tabular}{lcc}
\hline & S. cerevisiae & C. utilis \\
\hline Amino acid synthesis & 3772 & 4264 \\
$\quad$ polymerization & 1734 & 1960 \\
Carbohydrate synthesis & 3135 & 2329 \\
Lipid synthesis & 651 & 651 \\
RNA-synthesis and & & \\
polymerization & 341 & 341 \\
Turnover of m-RNA & 71 & 71 \\
NADPH generation & 0 & 0 \\
Transport: Carbon source & 0 & 0 \\
$\quad$ Pmmonium & 620 & 700 \\
$\quad$ photassium and & 240 & 240 \\
Total & & 10556 \\
Theoretical Yaxphorus & 9.5 & 9.5 \\
\hline
\end{tabular}

Data are expressed as mmol ATP. $100 \mathrm{~g}$ biomass $^{-1}$.

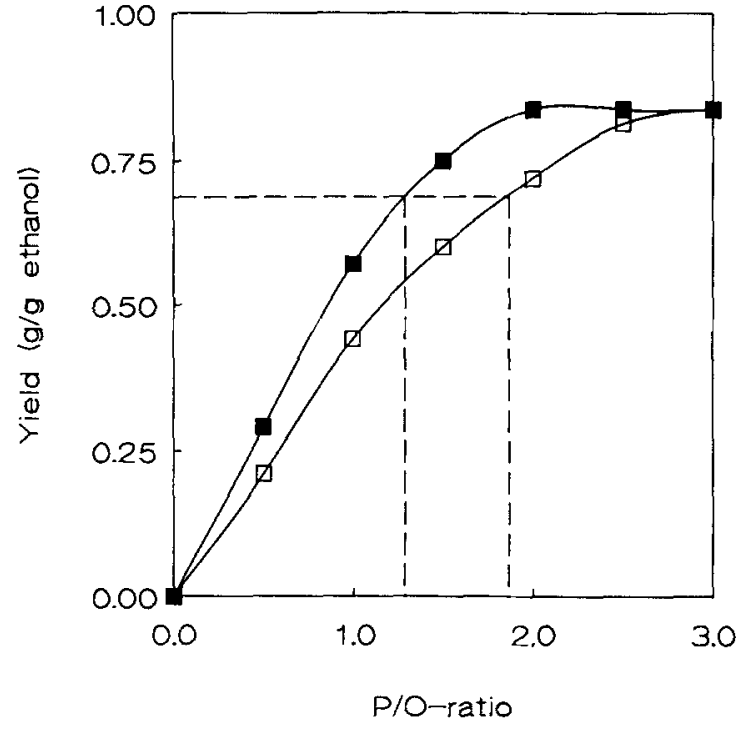

Fig. 2. Calculated cell yield ( $\mathrm{g}$ biomass $\cdot \mathrm{g}$ ethanol ${ }^{-1}$ ) as a function of the P/O-ratio for both $S$. cerevisiae and C. utilis, assuming that the difference between the theoretical and experimental $\mathrm{Y}_{\mathrm{ATP}}$ is given by a k-factor of $0.57(\square)$ or by a fixed difference of 2700 ATP $100 \mathrm{~g}^{\text {biomass }}{ }^{-1}(\square)$. The dashed line shows the observed cell yield of $C$. utilis and the corresponding $\mathrm{P} / \mathrm{O}$-ratios.

growth on glucose continues to increase with the $\mathrm{P} / \mathrm{O}$-ratio. The maximal attainable yield for growth on ethanol can be calculated from Equation 3 or 4 and is $1000 /(46.2 .584)=0.84 \mathrm{~g}$ biomass.g ethanol $^{-1}$. At this point, growth becomes carbon- rather than energy-limited. In contrast, growth on glucose (maximal attainable yield $0.68-0.72 \mathrm{~g}$ biomass.g glucose $e^{-1}$, equations 1 and 2) would still be energy-limited even if an effective $\mathrm{P} / \mathrm{O}$-ratio as high as 3.0 would be possible (Fig. 1).

For growth on acetate, the theoretical $Y_{A T P}^{\max }$ calculated for growth on ethanol can be used (Table 3 ). In all previous bioenergetic studies on growth on acetate, transport of acetate is regarded as an active, i.e. energy-requiring process. However, it should be realized that the proton taken up together with the acetate anion is subsequently used in metabolism. Therefore acetate transport should be treated as a passive (or facilitated) transport process. The effective $\mathrm{P} / \mathrm{O}$-ratios calculated for growth on acetate are 2.3 and 1.7 for $C$. utilis (k-factor and fixed difference, respectively) and 1.6 and 1.15 for S. cerevisiae. 


\section{Compartmentation and $\mathrm{P} / \mathrm{O}$-ratio}

In the calculation of the $\mathrm{P} / \mathrm{O}$-ratios as described above, the effective in vivo value has been obtained, irrespective of the nature of the reducing equivalents; i.e. the total amount of ATP required (corrected for substrate level phosphorylation) is divided by the total amount of reducing equivalents. It seems likely that the P/O-ratio is influenced by the relative fraction of mitochondrial versus cytosolic reducing equivalents. Unlike mammalian mitochondria, mitochondria from yeasts and plants can oxidize exogenously produced (i.e. cytosolic) reducing equivalents, in addition to the normal intramitochondrial oxidation (Møller \& Palmer 1981; Schuurmans Stekhoven 1966). Reducing equivalents are unable to cross the mitochondrial membrane, however (von Jagow \& Klingenberg 1970), and thus remain strictly separated, unless some form of shuttle operates. $S$. cerevisiae lacks energy conservation at site I (Ohnishi 1973) and hence possesses a virtually symmetrical electron transport chain. Therefore, it appears likely that the P/O-ratio of $S$. cerevisiae will not vary much for different substrates, since the localization or the nature of the reducing equivalents (FADH or $\mathrm{NADH}$ ) plays a minor role. For $C$. utilis, the situation is more complex, since in this organism oxidation of mitochondrial (but not cytosolic) NADH is coupled to the generation of energy at site I, as in mammals. Furthermore, mitochondrial NADH passes through one more energy-generating site (i.e. site I) than FADH.

With recent data on maximal $\mathrm{P} / \mathrm{O}$-ratios, obtained from studies with isolated (mainly mammalian) mitochondria, it is possible to calculate the mechanistic P/O-ratios for growth of $S$. cerevisiae and $C$. utilis on various carbon sources. It should be stressed that the values thus obtained have no direct meaning for the in vivo situation, due to the incomplete coupling of respiration and ATP generation as discussed above. However, such calculations will indicate to what extent the P/O-ratio may vary during growth on different substrates. Furthermore they will give an indication of the theoretical energy gain of an organism with three instead of two sites. A general overview of some recently reported values for the $\mathrm{P} / 2 \mathrm{e}$ ratios (ATP generated per passage of 2 electrons) for the various sites, as well as the overall maximal $\mathrm{P} / \mathrm{O}$-ratio is presented in Table 4. The P/2e data for sites I and II average 1.0 and 0.5 , respectively. Some variation is found for site III (the cytochrome $c$ oxidase). It has been suggested that the stoichiometry of site III is intrinsically variable, and that the number of protons translocated per 2 electrons is high at very low values of the proton-motive force (Murphy \& Brand 1988). The data in Table 4 depend on some assumptions regarding net $\mathrm{H}^{+} / \mathrm{ATP}$-stoichiometry of the mitochondrial ATPase, which is assumed to be 3, similar to the value for the bacterial enzyme (Kashket 1982). However, a further proton is required for the uptake of inorganic phosphate into the mitochondrion, so that the effective $\mathrm{H}^{+}$/ATP ratio is 4 for the mitochondrial enzyme (see Beavis 1987a for references). Data for P/O-ratios recently obtained with yeast mitochondria (Ouhabi et al. 1989) are in good agreement with the values for mammalian mitochondria. With these data, the mechanistic P/O-ratio for growth on glucose may be calculated. For these calculations the most commonly shown $\mathrm{P} / 2 \mathrm{e}$ data for the three sites have been taken, i.e. the $\mathrm{P} / 2 \mathrm{e}$ ratios are assumed to be $1,0.5$ and 1 for sites I, II and III, respectively. Thus the maximal P/O-ratio for oxidation of mitochondrial $\mathrm{NADH}$ is 2.5 (with three sites) and 1.5 for FADH, cytoplasmic NADH and mitochondrial NADH (in case only two sites are operative). In the case of $C$. utilis it is necessary to establish the localization of all reducing equivalents used in catabolic reactions. For reducing equivalents originating from anabolic reactions, a simplification has been made in that the amino acid biosynthesis, as starting from central mitochondrial metabolic precursors (KG, OAA), is assumed to be cytosolic. The localization of other reducing equivalents is mostly known. The total calculated number of reducing equivalents is virtually similar for both yeasts (Table 5). The overall mechanistic P/O-ratios for $S$. cerevisiae and C. utilis are 1.5 and 2.0, respectively (Table 5). Similar calculations for growth on ethanol are complicated by the fact that in yeasts several isoenzymes may occur of the first two enzymes involved in the metabolism of ethanol, alcohol dehydroge- 
Table 4. General overview of some recently reported values of ATP/2e for the various sites, and mechanistic P/O-ratio for isolated mitochondria.

\begin{tabular}{|c|c|c|c|c|c|}
\hline \multicolumn{3}{|c|}{ ATP/2e } & \multicolumn{2}{|c|}{ Mechanistic P/O } & \multirow[t]{2}{*}{ References } \\
\hline Site I & II & III & succinate- $\mathrm{O}_{2}$ & $\mathrm{NADH}-\mathrm{O}_{2}$ & \\
\hline \multicolumn{6}{|c|}{ Rat liver mitochondria } \\
\hline 1.0 & 0.5 & 1.0 & 1.5 & 2.5 & $\begin{array}{l}\text { Wikström (1984) } \\
\text { Mitchell et al. (1986) } \\
\text { Brown \& Brand (1988) }\end{array}$ \\
\hline 1.0 & 0.5 & 1.25 & 1.75 & 2.75 & Beavis $(1987 a, b)$ \\
\hline \multicolumn{6}{|c|}{ S. cerevisiae mitochondria } \\
\hline nd & nd & nd & $1.5^{*}$ & $1.5^{*}$ & Ouhabi et al. (1989) \\
\hline
\end{tabular}

* For mitochondrial NADH (oxidation of ethanol).

nd : not determined.

nases and acetaldehyde dehydrogenases. Alcohol dehydrogenases are found in the cytosol (at least two forms) and in the mitochondria (Branden et al. 1975; Fraenkel 1982). Acetaldehyde dehydrogenases are also found in both mitochondria and cytosol (Jacobson \& Bernofsky 1974; Llorente \& Núñez de Castro 1977). Indeed, even mitochondria isolated from glucose-limited chemostat cultures of $S$. cerevisiae grown at a low dilution rate oxidize both ethanol and acetaldehyde (van Urk et al. 1989). Furthermore, the next enzyme (acetyl-CoA synthetase, E.C. 6.2.1.1), which activates acetate, is generally thought to be mitochondrial (Satyanarayana \& Klein 1976), but has also been partially recovered in the microsomal fraction under certain cultivation conditions (Klein \& Jahnke 1971). However, the variation in the mechanistic P/Oratio can be calculated for two extreme cases. In

Table 5. Amount (mmol $100 \mathrm{~g}_{\text {biomass }}{ }^{-1}$ ) and localization ( $\%$ of total in parentheses) of reducing equivalents used in dissimilation, and overall calculated mechanistic $\mathrm{P} / \mathrm{O}$-ratio for aerobic glucose-limited chemostat growth of $S$. cerevisiae and $C$. utilis $\left(\mathrm{D}=0.10 \mathrm{~h}^{-1}\right)$.

\begin{tabular}{lccc}
\hline & S. cerevisiae & C. utilis \\
\hline Mitochondrial FADH & $627(12 \%)$ & $536(11 \%)$ \\
& NADH & $2888(56 \%)$ & $2559(53 \%)$ \\
Cytosolic $\quad$ NADH & $1673(32 \%)$ & $1769(36 \%)$ \\
Total reducing equivalents & 5188 & 4864 \\
Mechanistic P/O-ratio & 1.5 & 2.0 \\
\hline
\end{tabular}

the first case, both alcohol dehydrogenase and acetaldehyde dehydrogenase are taken as mitochondrial, and in the second case both are assumed to be cytosolic. Acetyl-CoA synthetase is assumed to be mitochondrial in both cases. Since a major part of the total number of reducing equivalents is formed in the conversion of ethanol to acetic acid, these two cases result in a large difference in the fraction of mitochondrial NADH: for C. utilis $77 \%$ and $28 \%$ of the total number of reducing equivalents, respectively. Nevertheless, the calculated mechanistic $\mathrm{P} / \mathrm{O}$-ratio differs by less than $30 \%: 2.3$ and 1.8 , respectively (calculations not shown). For $S$. cerevisiae a value of 1.5 is calculated. For acetate, the mechanistic $\mathrm{P} / \mathrm{O}$-ratios for $C$. utilis and $S$. cerevisiae are calculated to be 2.1 and 1.5 , respectively. The data on effective and mechanistic P/O-ratios have been summarized in Table 6 .

\section{Concluding remarks}

From the theoretical calculations on the mechanistic $\mathrm{P} / \mathrm{O}$-ratio shown above, it can be concluded that the mechanistic $\mathrm{P} / \mathrm{O}$-ratio is only affected to a small extent by the localization of the reducing equivalents used for dissimilatory purposes. This suggests that the $\mathrm{P} / \mathrm{O}$-ratio is largely independent of the carbon source (Table 6). Furthermore the calculations show that the mechanistic $\mathrm{P} / \mathrm{O}$-ratio in C. utilis is $30-50 \%$ higher than in $S$. cerevisiae 
(Table 6). These values can be compared to effective $\mathrm{P} / \mathrm{O}$-ratios as calculated from an experimental $\mathrm{Y}_{\mathrm{ATP}}$, which is estimated from a theoretical value by taking either a fixed fraction of this value (the $\mathrm{k}$-factor) or adding a fixed amount of ATP to the theoretical requirement. Only in the latter case, an approximately constant $\mathrm{P} / \mathrm{O}$-ratio is calculated, although all values for growth on acetic acid are significantly higher (Table 6). In the case of the use of a k-factor, very large differences in the effective $\mathrm{P} / \mathrm{O}$-ratio are calculated for different carbon sources, for instance $70 \%$ in the case of growth of $S$. cerevisiae on glucose and acetate (Table 6). In fact the values then become equal to the mechanistic P/O-ratio. However, it can be shown experimentally that the $\mathrm{P} / \mathrm{O}$-ratio of $C$. utilis is indeed higher than for $S$. cerevisiae: this is evident from the fact that the yield of $C$. utilis on ethanol and acetate is significantly higher than for $S$. cerevisiae (Table 1 ), despite the fact that the theoretical $Y_{\text {ATP }}$ for growth of both yeasts on these carbon sources is similar (Table 3). During growth on glucose, the higher $\mathrm{P} / \mathrm{O}$-ratio of $C$. utilis is masked by a lower $\mathrm{Y}_{\mathrm{ATP}}^{\max }$ due to the high protein content and the presence of an active transport system for glucose (Table 2). This results in the same yield as for $S$. cerevisiae (Table 1). Summarizing, the data presented here suggest that the gap between theoretical and experimental $\mathrm{Y}_{\text {ATP }}$ could be an approximately fixed amount of ATP.

The various methods to calculate $\mathrm{Y}_{\mathrm{ATP}}$ or $\mathrm{P} / \mathrm{O}$ - ratios all have their specific drawbacks. The data on theoretical $Y_{A T P}^{\max }$-values (Tables 2,3) are probably premature and incomplete. Nevertheless, they show that, for instance, the energy investment for synthesis of amino acids from ethanol is an order of magnitude higher than that for glucose (Tables 2, 3). Transport of metabolites across the plasma membrane of $C$. utilis makes up a significant fraction of the theoretical $Y_{A T P}^{\max }$ on glucose (Table 2).However, with respect to transport processes it should be kept in mind that eukaryotes have a high degree of compartmentation. This in turn necessitates extensive intracellular transport of metabolites and proteins across various membranes. The only intracellular transport process currently taken into account in theoretical studies of bioenergetics is that of phosphate required for oxidative phosphorylation. A further point which is difficult to assess is the actual cost of protein synthesis. Presently, a figure of 4 ATP per amino acid is used for elongation of a peptide chain. It should be realized that this is a minimum figure which does not take into account the energy costs of addition of incorrect amino acids to the chain or subsequent proofreading (cf. Lewin 1985; Stouthamer et al. 1990; Thompson 1988).

An uncertain factor is the potential role of pyrophosphate $\left(\mathrm{PP}_{\mathrm{i}}\right)$ in bioenergetics. It is well known that $P P_{i}$ can partly replace $\mathrm{ATP}$ in a number of bacteria (Gottschalk \& Andreesen 1979). More recently, it has been shown that many plants con-

Table 6. Effective P/O-ratios calculated from theoretical $\mathrm{Y}_{\mathrm{ATP}}^{\max }$-values for chemostat growth $\left(\mathrm{D}=0.10 \mathrm{~h}^{-1}\right)$ of $S$. cerevisiae and C. utilis on various carbon sources, assuming that the difference between the theoretical and the experimental $\mathrm{Y}_{\mathrm{ATP}}$ is given by a fixed factor $(\mathrm{k}=$ 0.57 ) or a fixed difference of $2700 \mathrm{mmol}$ ATP. $100 \mathrm{~g}_{\text {biomass }}{ }^{-1}$. The calculated mechanistic P/O-ratio is also shown.

\begin{tabular}{|c|c|c|c|c|c|c|}
\hline \multirow[t]{2}{*}{ C-source } & \multirow[t]{2}{*}{ Theor $\cdot Y_{\mathrm{A} T \mathrm{~m}}^{\max }$} & \multirow[t]{2}{*}{ Mechanistic $\mathrm{P} / \mathrm{O}$} & \multicolumn{2}{|c|}{ k-Factor } & \multicolumn{2}{|c|}{ Fixed difference } \\
\hline & & & $\mathbf{Y}_{\mathrm{ATP}}$ & $\mathrm{P} / \mathrm{O}$ & $\mathbf{Y}_{\text {ATP }}$ & $\mathrm{P} / \mathrm{O}$ \\
\hline \multicolumn{7}{|l|}{ S. cerevisiae } \\
\hline Glucose & 28.1 & 1.5 & 16.0 & 0.95 & 16.0 & 0.95 \\
\hline Ethanol & 9.5 & 1.5 & 5.4 & 1.5 & 7.6 & 1.0 \\
\hline Acetic acid & 9.5 & 1.5 & 5.4 & 1.6 & 7.6 & 1.15 \\
\hline \multicolumn{7}{|l|}{ C. utilis } \\
\hline Glucose & 20.8 & 2.0 & 11.9 & 1.5 & 13.3 & 1.4 \\
\hline Ethanol & 9.5 & $1.8-2.3^{*}$ & 5.4 & 1.9 & 7.6 & 1.3 \\
\hline Acetic acid & 9.5 & 2.1 & 5.4 & 2.1 & 7.6 & 1.6 \\
\hline
\end{tabular}

*Values with alcohol dehydrogenase(s) and acetaldehyde dehydrogenase(s) both cytosolic or both mitochondrial, respectively. 
tain a $\mathrm{PP}_{\mathrm{i}}$-phosphofructokinase and that they can generate a proton-motive force across vacuolar membranes by a $\mathrm{PP}_{\mathrm{i}}$-driven proton pump (reviewed by Taiz 1986). If for instance the mitochondrial pyrophosphatase of yeasts would function as a proton pump, this could have important implications for situations in which large amounts of $\mathrm{PP}_{\mathrm{i}}$ are formed, as occurs during growth on carbon sources which are assimilated via acetate. In this case the P/O-ratios for growth on ethanol and acetate as presented in Table 6 would have been overestimated.

Despite the limited knowledge of some cellular processes and the extensive cell compartmentation of eukaryotes it appears that facultatively anaerobic yeasts form a good model system for energetical studies. Most studies on bioenergetics of microorganisms have focussed on bacteria. However, bacteria exhibit heterofermentative anaerobic growth, which is associated with the production of large amounts of acids (e.g. Frankena et al. 1985) or homofermentative fermentation of glucose to for instance acetic acid (Schwartz \& Keller 1982). Acids, however, may uncouple energy generation from biomass formation (Baronofsky et al. 1984; Tuttle \& Dugan 1976; Verduyn et al. 1990b), although this probably depends to a major extent on the culture $\mathrm{pH}$. Alternatively, export of acids may yield energy under certain conditions, as shown for lactate efflux by Streptococcus cremoris (Otto et al. 1980). In contrast, yeasts only form two main fermentation products under anaerobic conditions, ethanol and glycerol, which are neutral and leave the cell by passive diffusion. This simple fermentation pattern facilitates the determination of $Y_{\text {ATP }}$ under various anaerobic growth conditions in chemostat cultures and reduces the chance of interference by acidic fermentation products. It can then be attempted to translate these data to aerobic situations.

\section{Acknowledgements}

This work was financed by a grant from The Netherlands Organization for Scientific Research (N.W.O.).

We thank Prof. Dr J.G. Kuenen and Prof. Dr
J.J. Heijnen for a critical reading of the manuscript.

\section{References}

Aiking H, Sterkenburg A \& Tempest DW (1977) Influence of specific growth limitation and dilution rate on the phosphorylation efficiency and cytochrome content of mitochondria of Candida utilis NCYC 321. Arch. Microbiol. 113: 65-72.

Babel W \& Müller RH (1985) Correlation between cell composition and carbon conversion efficiency in microbial growth: a theoretical study. Appl. Microbiol. Biotechnol. 22: 201-207

Barford JP \& Hall RJ (1979) An examination of the Crabtree effect in Saccharomyces cerevisiae: the role of respiratory adaptation. J. Gen. Microbiol. 114: 267-275

Baronofsky JJ, Schreurs WJA \& Kashket ER (1984) Uncoupling by acetic acid limits growth of and acetogenesis by Clostridium thermoaceticum. Appl. Environ. Microbiol. 48: 1134-1139

Bauchop T \& Elsden SR (1960) The growth of micro-organisms in relation to their energy supply. J. Gen. Microbiol. 23: 457-469

Beavis AD (1987a) Upper and lower limits of the charge translocation stoichiometry of mitochondrial electron transport. J. Biol. Chem. 262: 6165-6173

- (1987b) Upper and lower limits of the charge translocation stoichiometry of cytochrome $c$ oxidase. J. Biol. Chem. 262: 6174-6181

Beudeker RF, van Dam HW, van der Plaat JB \& Vellenga K (1990) Developments in baker's yeast production. In: Verachtert $\mathrm{H} \&$ De Mot $\mathrm{R}$ (Eds) Yeast Biotechnology and Biocatalysis (pp 103-145). Marcel Dekker Inc., New York \& Basel

Branden CI, Jornvall H, Eklund H \& Furugren B (1975) Aicohol dehydrogenases. In: Boyer PD (Ed) The Enzymes, Vol XI A (pp 103-190) Academic Press, New York

Brown CM \& Rose AH (1969) Effects of temperature on composition and cell volume of Candida utilis. J. Bacteriol. 97: 261-272

Brown GC \& Brand MD (1988) Proton/electron stoichiometry of mitochondrial complex I estimated from the equilibrium thermodynamic force ratio. Biochem. J. 252: 473-479

Bruinenberg PM, van Dijken JP \& Scheffers WA (1983) An enzymic analysis of NADPH production and consumption in Candida utilis. J. Gen. Microbiol. 129: 965-971

Dijkhuizen L, Wiersma M \& Harder W (1977) Energy production and growth of Pseudomonas oxalaticus OX1 on oxalate and formate. Arch. Microbiol. 115: 229-236

Eddy AA \& Hopkins PG (1985) The putative electrogenic nitrate-protonsymport of the yeast Candida utilis. Comparison with the systems absorbing glucose or lactate. Biochem. J. 231: 291-297

Evans CT, Scragg AH \& Ratledge C (1983) A comparative 
study of citrate efflux from mitochondria of oleaginous and non-oleaginous yeasts. Eur. J. Biochem. 130: 195-204

Fiechter A \& von Meyenburg HK (1969) Regulatory properties of growing cell populations of Saccharomyces cerevisiae in a continuous culture system. In: Kocková-Kratochvílová A (Ed) Yeasts. The proceedings of the 2nd Symposium on Yeasts (pp 387-398). Slovenskej Akademie Vied, Bratislava

Fraenkel DG (1982) Carbohydrate metabolism. In: Strathern JN, Jones EW \& Broach JR (Eds) The Molecular Biology of the Yeast Saccharomyces, Metabolism and Gene Expression (pp 1-37). Cold Spring Harbor, New York

Frankena J, van Verseveld HW \& Stouthamer AH (1985) A continuous culture study of the bioenergetic aspects of growth and production of exocellular protease in Bacillus licheniformis. Appl. Microbiol. Biotechol. 22: 169-176

Furukawa K, Heinzle E \& Dunn IJ (1983) Influence of oxygen on the growth of Saccharomyces cerevisiae in continuous culture. Biotechnol. Bioeng. 25: 2293-2317

Gommers PJF, van Schie BJ, van Dijken JP \& Kuenen JG (1988) Biochemical limits to microbial growth yields: An analysis of mixed substrate utilization. Biotechnol. Bioeng. 32: $86-94$

Gottschalk G \& Andreesen JR (1979) Energy metabolism in anaerobes. In: Quayle JR (Ed) Microbial Biochemistry 21 (pp 85-115). University Park Press, Baltimore

Gunter TE \& Jensen BD (1986) The efficiencies of the component steps of oxidative phosphorylation. Arch. Biochem. Biophys. 248: 289-304

Harder W \& van Dijken (1976) Theoretical considerations on the relation between energy production and growth of methane-utilizing bacteria. In: Schlegel HG, Gottschalk G \& Pfennig $\mathbf{N}$ (Eds) Microbial Production and Utilization of Gases $\left(\mathrm{H}_{2}, \mathrm{CH}_{4}, \mathrm{CO}\right.$ ) (pp 403-418). E Goltze KG, Göttingen

Harder W, van Dijken JP \& Roels JA (1981) Utilization of energy in methylotrophs. In: Dalton $H(E d)$ Microbial Growth on C1 Compounds (pp 258-269). Heyden, London

Haukelie AD \& Lie S (1971) Molar growth yields of yeasts in anaerobic batch cultures. J. Gen. Microbiol. 69: 135-141

Jacobson MK \& Bernofsky C (1974) Mitochondrial acetaldehyde dehydrogenase from Saccharomyces cerevisiae. Biochim. Biophys. Acta 350: 277-291

Kashket ER (1982) Stoichiometry of the $\mathrm{H}^{+}$-ATPase of growing and resting aerobic Escherichia coli. Biochemistry 21: 55345538

Klein HP \& Jahnke L (1971) Variations in the localization of acetyl-coenzyme. A synthetase in aerobic yeast cells. J. Bacteriol. 106: 596-602

Kormančíková V, Kováč L \& Vidová M (1969) Oxidative phosphorylation in yeast. V. Phosphorylation efficiencies in growing cells determined from molar growth yields. Biochim. Biophys. Acta 180: 9-17

Lagunas R (1976) Energy metabolism of Saccharomyces cerevisiae: discrepancy between ATP balance and known metabolic functions. Biochim. Biophys. Acta 440: 661-674

Lagunas R \& Ruiz E (1988) Balance of production and con- sumption of ATP in ammonium-starved Saccharomyces cerevisiae. J. Gen. Microbiol. 134: 2507-2511

Lang JM \& Cirillo VP (1987) Glucose transport in a kinaseless Saccharomyces cerevisiae mutant. J. Bacteriol. 169: 29322937

Lewin B (1985) The ribosome translation factory. In: Genes II (pp 150). J Wiley \& Sons, New York, Chichester, Brisbane, Toronto \& Singapore

Light PA \& Garland PB (1971) A comparison of mitochondria from Torulopsis utilis grown in continuous culture with glycerol, iron, ammonium, magnesium or phosphate as the growth-limiting nutrient. Biochem. J. 124: 123-134

Llorente N \& Núñez de Castro I (1977) Physiological role of yeasts $\mathrm{NAD}(\mathrm{P})^{+}$and $\mathrm{NADP}^{+}$-linked aldehyde dehydrogenases. Rev. Esp. Fisiol. 33: 135-142

Malpartida F \& Serrano R (1981) Proton translocation catalyzed by the purified yeast plasma membrane ATPase reconstituted in liposomes. FEBS Lett. 131: 351-354

Mitchell R, West IC, Moody AJ \& Mitchell P (1986) Measurement of the proton-motive stoichiometry of the respiratory chain of rat liver mitochondria: the effect of $N$-ethylmaleimide. Biochim. Biophys. Acta 849: 229-235

Møller IM \& Palmer JM (1981) Properties of the oxidation of exogenous NADH and NADPH by plant mitochondria. Evidence against a phosphatase or a nicotinamide nucleotide transhydrogenase being responsible for NADPH oxidation. Biochim. Biophys. Acta 638: 225-233

Murphy MP \& Brand MD (1988) Membrane-potential-dependent changes in the stoichiometry of charge translocation by the mitochondrial electron transport chain. Eur. J. Biochem. 173: 637-644

Nelson N \& Taiz L. (1989) The evolution of $\mathrm{H}^{+}$-ATPases. TIBS 14: $113-116$

Ohnishi T (1973) Mechanism of electron transport and energy conservation in the site I region of the respiratory chain. Biochim. Biophys. Acta 301: 105-128

Otto R, Sonnenberg ASM, Veldkamp H \& Konings WN (1980) Generation of an electrochemical proton gradient in Streptococcus cremoris by lactate efflux. Proc. Natl. Acad. Sci. USA 77: 5502-5506

Ouhabi R, Rigoulet M \& Guerin B (1989) Flux-yield dependence of oxidative phosphorylation at constant $\triangle \mu \mathrm{H}^{+}$. FEBS Lett. 254: 199-202

Oura E (1972) The effect of aeration on the growth energetics and biochemical composition of baker's yeast. Ph.D.thesis, University of Helsinki, Finland

Peinado JM, Cameira-Dos-Santos PJ \& Loureiro-Días MC (1989) Regulation of glucose transport in Candida utilis. J. Gen. Microbiol. 135: 195-201

Perlin DS, San Francisco MJD, Slayman CW \& Rosen BP (1986) $\mathrm{H}^{+} /$ATP stoichiometry of proton pumps from $\mathrm{Neu}$ rospora crassa and Escherichia coli. Arch. Biochem. Biophys. 248: 53-61

Pirt SJ (1965) The maintenance energy of bacteria in growing cultures. Proc. Roy. Soc. London B163: 224-231

Postma E, Scheffers WA \& van Dijken JP (1988) Adaptation of 
the kinetics of glucose transport to environmental conditions in the yeast Candida utilis CBS 621: a continuous-culture study. J. Gen. Microbiol. 134: 1109-1116

Postma E, Verduyn C, Scheffers WA \& van Dijken JP (1989) Enzymic analysis of the Crabtree effect in glucose-limited chemostat cultures of Saccharomyces cerevisiae. Appl. Environ. Microbiol. 55: 468-477

Rieger M, Käppeli O \& Fiechter A (1983) The role of limited respiration in the incomplete oxidation of glucose by Saccharomyces cerevisiae. J. Gen. Microbiol. 129: 653-661

Roels JA (1983) Biochemically structured balances of microbial metabolism. In: Energetics and Kinetics in Biotechnology (pp 99-128). Elsevier Science Publishers, Amsterdam

Romano AH (1982) Facilitated diffusion of 6-deoxy-D-glucose in bakers' yeast: evidence against phosphorylation-associated transport of glucose. J. Bacteriol. 152: 1295-1297

Satyanarayana T \& Klein HP (1976) Studies on the 'aerobic' acetyl CoA-synthetase of Saccharomyces cerevisiae: purification, crystallization, and physical properties of the enzyme. Arch. Biochem. Biophys. 174: 480-490

Schatzmann H (1975) Anaerobes Wachstum von Saccharomyces cerevisiae. Ph.D.thesis, Eidgenössische Technische Hochschule Zürich, Switzerland

Schuurmans Stekhoven FMAH (1966) Studies on yeast mitochondria. I. Existence of three phosphorylation sites along the respiratory chain of isolated yeast mitochondria. Arch. Biochem. Biophys. 115: 555-568

Schwarz RD \& Keller FA (1982) Acetic acid production by Clostridium thermoaceticum in $\mathrm{pH}$-controlled batch fermentations at acidic pH. Appl. Env. Microbiol. 43: 1385-1392

Shul'govskaya EM, Pozmogova IN \& Rabotnova IL (1988) Growth of a culture of Candida utilis in the chemostat on a balanced medium. Microbiology 56: 496-499

Stouthamer AH (1973) A theoretical study on the amount of ATP required for synthesis of microbial cell material. Antonie van Leeuwenhoek 39: 545-565

Stouthamer AH \& Bettenhaussen CW (1975) Determination of the efficiency of oxidative phosphorylation in continuous cultures of Aerobacter aerogenes. Arch. Microbiol. 102: 187-192

Stouthamer AH (1979) The search for correlation between theoretical and experimental growth yields. In: Quayle JR (Ed) International Review of Biochemistry. Microbial Biochemistry Vol 21 (pp 1-46). University Park Press, Baltimore

Stouthamer AH, Bulthuis BA \& van Verseveld HW (1990) Energetics of growth at low growth rates and its relevance for the maintenance concept. In: Bazin MJ \& Poole RK (Eds) Microbial Growth Dynamics (pp 85-102). Oxford University Press, Oxford

Stucki JW (1980) The optimal efficiency and the economic degrees of coupling of oxidative phosphorylation. Eur. J. Biochem. 109: 269-283

Taiz L (1986) Are biosynthetic reactions in plant cells thermodynamically coupled to glycolysis and the tonoplast proton motive force? J. Theor. Biol. 123: 231-238

Tempest DW \& Neijssel OM (1984) The status of $Y_{\text {ATP }}$ and maintenance energy as biologically interpretable phenomena. Annual Rev. Microbiol. 38: 459-486

Thompson RC (1988) EFTu provides an internal kinetic standard for translational accuracy. TIBS 13: 91-93

Tuttle JH \& Dugan PR (1976) Inhibition of growth, iron, and sulfur oxidation in Thiobacillus ferrooxidans by simple organic compounds. Can. J. Microbiol. 22: 719-730

Van Dijken JP \& Harder W (1975) Growth yields of microorganisms on methanol and methane. A theoretical study. Biotechnol. Bioeng. 17: 15-30

Van Dijken JP \& Scheffers WA (1986) Redox balances in the metabolism of sugars by yeasts. FEMS Microbiol. Rev. 32: 199-224

Van Gent-Ruijters MLW, de Vries W \& Stouthamer AH (1975) Influence of nitrate on fermentation pattern, molar growth yields and synthesis of cytochrome b in Propionibacterium pentosaceum. J. Gen. Microbiol. 88: 36-48

Van Urk H, Mak PR, Scheffers WA \& van Dijken JP (1988) Metabolic responses of Saccharomyces cerevisiae CBS 8066 and Candida utilis CBS 621 upon transition from glucose limitation to glucose excess. Yeast 4: 283-291

Van Urk H, Bruinenberg PM, Veenhuis M, Scheffers WA \& van Dijken JP (1989) Respiratory capacities of mitochondria of Saccharomyces cerevisiae CBS 8066 and Candida utilis CBS 621 grown under glucose limitation. Antonie van Leeuwenhoek 56: 211-220

Verduyn C, van Dijken JP \& Scheffers WA (1984) Colorimetric alcohol assays with alcohol oxidase. J. Microbiol. Meth. 2: 15-25

Verduyn C, Postma E, Scheffers WA \& van Dijken JP (1990a) Physiology of Saccharomyces cerevisiae in anaerobic glucoselimited chemostat cultures. J. Gen. Microbiol. 136: 395-403

- (1990b) Energetics of Saccharomyces cerevisiae in anaerobic glucose-limited chemostat cultures. J. Gen. Microbiol. 136: 405-412

Von Jagow G \& Klingenberg M (1970) Pathways of hydrogen in mitochondria of Saccharomyces carlbergensis. Eur. J. Biochem. 12: 583-592

Von Meyenburg HK (1969) Energetics of the budding cycle of Saccharomyces cerevisiae during glucose limited aerobic growth. Arch. Mikrobiol. 66: 289-303

Wikström M (1984) Two protons are pumped from the mitochondrial matrix per electron transferred between NADH and ubiquinone. FEBS Lett. 169: 300-304 